\title{
Effect of moisture content on the permeability of tailing sand samples gathered from ex tin mines in Perak state Malaysia
}

\begin{abstract}
Tailing sand is one of the residue minerals obtained after tin extraction. It contains silica in between $94 \%$ and $99.5 \%$ and available in abundance at the Kinta Valley, Perak State, Malaysia. Permeability is one of the important molding sand properties and considered much in the sand casting mold preparation. This molding sand property plays a vital role in the sand casting process and helps to remove the gases during the casting processing. In this research work, samples of tailing sands were gathered from four identified ex tin mines located at the Perak State, Malaysia. They were investigated by the standard sand testing procedures prescribed by the American Foundrymen Society (AFS). Sand specimens of size $\varnothing 50 \mathrm{~mm} \times 50$ $\mathrm{mm}$ in height from various sandï water ratios bonded with $4 \%$ and $8 \%$ clay were compacted on applying three ramming blows of $6666 \mathrm{~g}$ each by using a Ridsdale-Dietert metric standard rammer. The specimens were tested for permeability number with the aid of a RidsdaleDietert permeability meter. Before the tests were conducted, the moisture content was measured by using a moisture analyzer. The results were compared with the properties of the molding sand samples collected from RCS Manufacturing Sdn. Bhd., the company supplying sand to the Proton Casting unit car manufacturing company. The molding sand sample sample bonded with $8 \%$ clay was found to have maximum permeability with an optimum allowable moisture content range of 3.5-6.0\% and for the sand mixture bonded with $4 \%$ clay at $3.0-3.5 \%$ moisture.
\end{abstract}

Keyword: Tailing sand; Clay content; Moisture content; Permeability 